\title{
The Bristol third stage trial: active versus physiological management of third stage of labour
}

\author{
Walter J Prendiville, Joanna E Harding, Diana R Elbourne, Gordon M Stirrat
}

\begin{abstract}
Objective-To compare the effects on fetal and maternal morbidity of routine active management of third stage of labour and expectant (physiological) management, in particular to determine whether active management reduced incidence of postpartum haemorrhage.
\end{abstract}

Design-Randomised trial of active versus physiological management. Women entered trial on admission to labour ward with allocation revealed just before vaginal delivery. Five months into trial high rate of postpartum haemorrhage in physiological group $(16.5 \%$ v $3.8 \%)$ prompted modification of protocol to exclude more women and allow those allocated to physiological group who needed some active management to be switched to fully active management. Sample size of 3900 was planned, but even after protocol modification a planned interim analysis after first $\mathbf{1 5 0 0}$ deliveries showed continuing high postpartum haemorrhage rate in physiological group and study was stopped.

Setting-Maternity hospital.

Participants-Of 4709 women delivered from 1 January 1986 to 31 January 1987, 1695 were admitted to trial and allocated randomly to physiological (849) or active (846) management. Reasons for exclusion were: refusal, antepartum haemorrhage, cardiac disease, breech presentation, multiple pregnancy, intrauterine death, and, after May 1986, ritodrine given two hours before delivery, anticoagulant treatment, and any condition needing a particular management of third stage.

Interventions-All but six women allocated to active management actually received it, having prophylactic oxytocic, cord clamping before placental delivery, and cord traction; whereas just under half those allocated to physiological management achieved it. A fifth of physiological group received prophylactic oxytocic, two fifths underwent cord traction and just over half clamping of the cord before placental delivery.

Endpoint-Reduction in incidence of postpartum haemorrhage from $\mathbf{7 . 5 \%}$ under physiological management to $5.0 \%$ under active management.

Measurements and main results-Incidence of postpartum haemorrhage was $5.9 \%$ in active management group and $17.9 \%$ in physiological group (odds ratio $3 \cdot 13 ; 95 \%$ confidence interval $2 \cdot 3$ to $4 \cdot 2$ ), a contrast reflected in other indices of blood loss. In physiological group third stage was longer (median $15 \mathrm{~min} v 5 \mathrm{~min}$ ) and more women needed therapeutic oxytocics $(29.7 \% v 6.4 \%)$. Apgar scores at one and five minutes and incidence of neonatal respiratory problems were not significantly different between groups. Babies in physiological group weighed mean of $85 \mathrm{~g}$ more than those in active group. When women allocated to and receiving active management (840) were compared with those who actually received physiological management (403) active management still produced lower rate of postpartum haemorrhage (odds ratio 2.4 ; $95 \%$ CI 1.6 to $3 \cdot 7)$.

Conclusions-Policy of active management practised in this trial reduces incidence of postpartum haemorrhage, shortens third stage, and results in reduced neonatal packed cell volume.

\section{Introduction}

In 1984 a survey of policies for the care of obstetrically normal women in maternity units in England showed that a policy of active management (giving oxytocin-ergometrine, clamping the cord early, and applying controlled cord traction) was virtually universal in those units that were known to have a policy for managing the third stage of labour. ${ }^{1}$ Two out of 238 consultant units reported that one or more obstetricians used oxytocin rather than oxytocinergometrine routinely. Some general practitioner and consultant units reported that they offered women a choice about management of the third stage in their discussion of the birth plan, and others reported that their policy was to use active management except when women requested otherwise.

Active management has recently been challenged ${ }^{23}$ because obstetric routines have come under general attack and because its scientific basis, particularly the use of prophylactic oxytocics, has been questioned. Dunn et al have shown that these obstetric practices may interfere with physiological processes to the detriment of both mother and baby..$^{48}$ More recently, Inch suggested that routine active management of the third stage of labour promotes a cascade of intervention through which controlled cord traction becomes necessary because $(a)$ women are delivered of the placenta without the aid of gravity, $(b)$ the umbilical cord is clamped early and routinely, and $(c)$ a prophylactic oxytocic has been administered. ${ }^{9}$ These contentions have not been tested in a randomised controlled trial.

A review of controlled trials in which routine use of an oxytocic was compared with either a placebo or no routine prophylactic suggested that oxytocic drugs reduce the risk of postpartum haemorrhage and the need for therapeutic oxytocics but increase the risk of hypertension. ${ }^{10}$ Many of the papers on which this analysis was based, however, did not study other aspects of the management of the third stage of labour.

In 1984 Romney and White called for a "relook at masterly inactivity in a proper controlled trial . . . before the best exponents of non-active management have retired from service." The purpose of the Bristol third stage trial, therefore, was to determine whether, in terms of maternal and fetal morbidity, continuing with routine active rather than expectant (physio-
Correspondence to: Ms Elbourne. 
logical) management of the third stage of labour was justified.

\section{Patients and methods}

All women who were expected to deliver vaginally in Bristol Maternity Hospital during the period of the trial were eligible to enter. The principal criteria for exclusion when the main trial began in January 1986 were refusal to participate, cardiac disease, antepartum haemorrhage, breech presentation, multiple pregnancy, and intrauterine death. In addition, midwives and obstetricians did not enter women if they thought that there were good reasons for excluding them. These reasons were fully documented.

In the antenatal clinic women were given a leaflet explaining the trial, asking them to return a slip if they did not wish to take part, and telling them where they could get further information about the trial. On admission to the labour ward women who were eligible were reminded about the trial. Those who agreed to participate had their names entered into a register of trial numbers. Correspondingly numbered, sealed opaque envelopes were placed in the women's notes. When the midwife or obstetrician was ready to prepare for delivery the time was recorded on the outside of the envelope. The envelope was then opened and showed which of two methods of management the woman had been randomly allocated to.

All women for whom an envelope was opened were deemed to have entered the trial and were followed up regardless of subsequent management. Women who became ineligible after being entered into the register but before the envelope was opened were deemed not to have entered the trial and were not included in the analysis. Their envelopes were returned unopened to the trial coordinator and the criteria for exclusion noted. The envelopes contained one of two sets of instructions: attempt to manage the third stage actively or attempt to allow physiological delivery of the placenta (box).

The primary hypothesis tested by the trial was that active management reduces the incidence of postpartum haemorrhage (blood loss $\geqslant 500 \mathrm{ml}$ ) compared with physiological management. If active management reduced this incidence from $7 \cdot 5 \%$ under physiological management to $5 \cdot 0 \%$ (as existed in 1983 in the Bristol Maternity Hospital under a system of active management) then a sample size of 3900 would give an $80 \%$ chance of detecting this difference at $\mathrm{p} \leqslant 0.05$. An independent data monitoring committee (comprising an obstetrician, a midwife, and an epidemiologist) was established, and an interim analysis was planned on data from roughly the first 1500 mothers and babies, firstly, to provide a better estimate of the incidence of postpartum haemorrhage under physiological management and, secondly, to check that there were no clinically important adverse effects of either management policy.

In addition to determining the incidence of postpartum haemorrhage and more objective measures of maternal blood loss the trial aimed at testing the effect of the different management policies on other maternal variables. These were the length of the third stage; the need for therapeutic oxytocics, manual removal of the placenta, and evacuation of retained products of conception; and side effects of the oxytocics such as nausea, headaches, and hypertension. Neonatal variables considered were the Apgar score, packed cell volumes $(<0.50$ or $>0.65)$, admission to a special care nursery, jaundice, and breast feeding.

Data on these variables, the trial population, including factors that might modify the effect of the management policy, and the actual management of the third stage were available from the routine

\section{Details of management \\ ACTIVE MANAGEMENT}

Attempt to manage the third stage actively:

- Try to give one ampoule of the oxytocic (5 units oxytocin and $0.5 \mathrm{mg}$ ergometrine maleate routinely or 10 units synthetic oxytocin if the mother has raised blood pressure) immediately after delivery of the anterior shoulder

- Try to clamp the cord 30 seconds after delivery of the baby

- When the uterus has contracted try to deliver the placenta by controlled cord traction with a protective hand on the abdomen helping to shear off the placenta and preventing uterine inversion

- Try not to give any special instructions about posture.

If placenta is retained after one hour:

- Ensure the bladder is empty

- Reattempt delivery by active management

- Remove placenta manually under general anaes thetic or epidural block.

PHYSIOLOGICAL MANAGEMENT

Try to allow physiological delivery of the placenta:

- Try not to give an oxytocic

- Try to leave the cord attached to the baby until the

placenta is delivered

- Try not to use controlled cord traction or any manual interference with the uterus at the fundus

- Try to encourage the mother to concentrate on feeling for the next contraction or an urge to push

- When the mother feels this contraction or an urge to push or there are signs of separation encourage maternal effort and encourage the mother to adopt a posture aiding delivery by gravity - that is, standing, kneeling, on all fours, squatting, sitting on a bed pan

- If the placenta does not deliver spontaneously wait, try putting the baby to the breast, and encourage maternal effort as above.

\section{SPECIAL CIRCUMSTANCES}

- Cord has to be clamped and cut before placental delivery (for example, for meconium stained liquor, cord round the neck): release blood from placental end into a kidney dish

- Forceps delivery: repair the episiotomy first and then deliver placenta physiologically

- Epidurals necessary: midwife should rest hand on fundus to wait for contraction but should not intervene. Posture will depend on whether the mother can get into a position that allows gravitational forcefor example, sitting on a bed pan, kneeling with help from partner

- Placenta retained after one hour: ensure bladder is empty; reattempt physiological delivery with gentle fundal pressure; manage actively - that is, give an oxytocic, clamp cord, and use controlled cord traction; remove placenta manually under general anaesthetic or epidural block.

computerised data collection system at the hospital. ${ }^{12}$ The files were rendered anonymous and transferred to the national perinatal epidemiology unit for analysis. Additional information about subsequent evacuation of retained products of conception was obtained from all the hospitals in the Frenchay and the Bristol and Weston health districts. Questionnaires asking for the views of staff and mothers were sent to a subsample towards the end of the trial.

The Bristol and Weston Health Authority ethics committee approved the study.

Continuous data were analysed with the $t$ test. For categorial data the $\chi^{2}$ test with Yates's correction was used to compare methods of management, and odds 
ratios and their $95 \%$ confidence intervals were used to compare results between the groups. ${ }^{13}$

\section{INTERIM ANALYSES}

After a run in period, which included training of staff in late 1985, the main trial began in January 1986. In April concerns about the high incidence of postpartum haemorrhage in the group allocated to physiological management prompted an early meeting of the data monitoring committee: a preliminary analysis (based on 425 deliveries up to the middle

TABLE I-Reasons for not entering 3014 women into trial ${ }^{\star}$

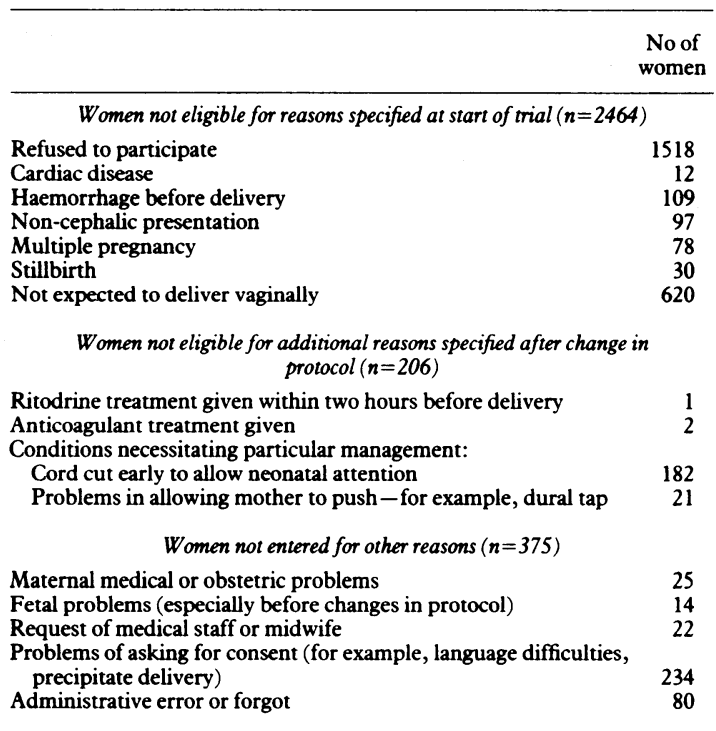

$\star$ For some women there was more than one reason for not entering trial.

TABLE II - Comparability of groups at entry to trial according to allocation

\begin{tabular}{lcc} 
& $\begin{array}{c}\text { Physiological } \\
\text { management group } \\
(\mathbf{n}=849)\end{array}$ & $\begin{array}{c}\text { Active } \\
\text { management group } \\
(\mathbf{n}=846)\end{array}$ \\
\hline Sociodemographic variables: & & \\
Mean (SD) maternal age (years) & $27 \cdot 4(5 \cdot 1)$ & $27 \cdot 2(5 \cdot 1)$ \\
No married & 691 & 672 \\
No primiparous & 372 & 409 \\
Obstetric history: & $47 / 477$ & $38 / 437$ \\
No with third stage problems previously & & $2 / 782$ \\
Antenatal variables: & $0 / 760$ & $117(9)$ \\
No with haemoglobin $590 \mathrm{~g} / 1$ & $117(9)$ & 717 \\
Mean (SD) haemoglobin (g/1) & 731 & 232 \\
Variables of labour: & 205 & $95 / 538$ \\
No with spontaneous onset & $117 / 541$ & $281 \cdot 8(214)$ \\
No given oxytocic for induction or augmentation & $277 \cdot 1(222)$ & 115 \\
No given epidural anaesthetic during 1st or 2nd stage & 98 & 722 \\
Mean (SD) length of lst and 2nd stage (minutes) & 743 & 659 \\
No who had cord clamped before baby delivered & 639 & $340 / 538$ \\
No who had spontaneous delivery & $335 / 541$ & 21 \\
No who had episiotomy or tear requiring suture & & $40 \cdot 0(12 \cdot 2)$ \\
No with low risk lst and 2nd stages of labour* & 17 & 447 \\
Baby: & $40 \cdot 1(11 \cdot 5)$ & \\
No with gestational age <37 weeks & 439 & \\
Mean (SD) gestational age (weeks) & & \\
No male & &
\end{tabular}

^Spontaneous onset, no augmentation, no epidural, no labour $>12$ hours, and spontaneous delivery.

TABLE III - Actual management during third stage of labour in women allocated to physiological or active management

\begin{tabular}{lcc}
\hline & $\begin{array}{c}\text { Physiological } \\
\text { management group } \\
(\mathbf{n}=849)\end{array}$ & $\begin{array}{c}\text { Active } \\
\text { management group } \\
(\mathbf{n}=846)\end{array}$ \\
\hline Prophylactic oxytocic given & 168 & 838 \\
Cord clamped before placental delivery & 437 & 838 \\
Cord traction & 336 & 839 \\
Management actually as allocated & 403 & 840 \\
If cord clamped before placental delivery, placental end released & $138 / 437$ & $47 / 838$ \\
Mother adopted posture to use gravity to help & 416 & 217 \\
Baby put to breast within 10 minutes & 225 & 63 \\
\hline
\end{tabular}

$\star$ Physiological = no prophylactic oxytocic given, cord not clamped until after placenta delivered, and no cord traction given; active = prophylactic oxytocic given, cord clamped before placenta delivered, and cord traction given. of February 1986) showed that the incidence of postpartum haemorrhage was notably higher in the physiological group $(16.5 \% ; 35 / 212)$ than the active group $(3 \cdot 8 \% ; 8 / 213)$ (odds ratio $4 \cdot 1 ; 95 \%$ confidence interval $2 \cdot 2$ to $7 \cdot 6$ ). A disproportionate number of these haemorrhages seemed to have occurred in cases in which physiological management, though randomly allocated, had not been possible-for example, the cord had had to be cut early because it was tightly around the baby's neck or there had been worries about meconium aspiration or the poor condition of the baby at birth. Also, early breast feeding was reported for only a small proportion of this group, though this might have been because the mother and her baby had been separated to allow paediatric care.

The committee therefore recommended that, though there were insufficient data to conclude that active management was preferable, there was sufficient evidence to recommend that the trial protocol should be modified. Accordingly several changes were made to the protocol from May 1986. Three extra criteria for exclusion from the trial were added-namely, ritodrine given within two hours before delivery, anticoagulant treatment given, and any condition (known before the envelope was opened) that would necessitate a particular management of the third stage, such as early cutting of the cord if there was meconium in the liquor or a need to avoid maternal effort after a dural tap. In addition, if a woman had been allocated to physiological management but there was a clear need to interrupt this (for example, when the unexpectedly poor condition of the baby necessitated early clamping of the cord) the management thereafter became active. In these circumstances and in the case of exclusions the reasons were carefully documented. The committee also advised staff to renew their attempts to encourage early breast feeding, particularly in the physiological group.

The data monitoring committee met on three subsequent occasions (July 1986, December 1986, January 1987) to examine additional months' data and in January 1987 recommended that the trial should be stopped. This recommendation was accepted.

Results

During the period of the main trial (1 January 1986 to 31 January 1987) babies of 4709 women were delivered in the hospital. Table I shows details of the 3014 (64\%) women not entered into the trial. The total population in the trial consisted of 1695 women, of whom 849 were randomly allocated to physiological and 846 to active management. Table II shows that the women in the two groups were comparable at entry.

Table III describes the actual management of the third stage of labour and shows a clear separation of the two policies. Virtually all ( $99 \%)$ of the women allocated to active management received this, having a prophylactic oxytocic, cord clamping before placental delivery, and cord traction. In contrast only one fifth of the group allocated to physiological management were given a prophylactic oxytocic, two fifths had cord traction, and just over half had the cord clamped before the placenta was delivered (and in $32 \%$ of those the placental end of the cord was released). In addition, half of this group attempted postures in which gravity could play a part at some time during the third stage, and over a quarter put their baby to the breast within the first 10 minutes after delivery, compared with $26 \%$ and $8 \%$ respectively in the group allocated to active management. In terms of use of prophylactic oxytocics, timing of cord clamping, and use of cord traction nearly half of the women in the physiological group actually achieved a physiological third stage, compared with only two women in the active group. 
The reasons for the differences between the management allocated and that received were elicited from the midwives' routine data and an examination of case notes by one of us $(\mathrm{JH})$. More than one reason was given in some instances. In the group who were allocated to physiological management but received some active management $(n=446)$ the reasons were heavy bleeding (95), cord cut before baby delivered (94), meconium (68), resuscitation of baby (59), placenta not delivered after one hour (57), late maternal refusal (30), other (25), and reason not given (15). In the active group there was one late maternal refusal, three other reasons, and for two women the reason was not given.

Table IV shows the results in terms of outcome. The incidence of postpartum haemorrhage in the group allocated to active management was $5 \cdot 9 \%$, which was near the predicted rate of $5 \%$. In the group allocated to physiological management the rate was $17 \cdot 9 \%$, which was more than double the estimate used in the primary hypotheses to calculate the required sample size with a power of $80 \%$. Thus the odds ratio of such haemorrhage with a policy of physiological rather than active management was $3 \cdot 13$ (95\% confidence interval $2 \cdot 3$ to $4 \cdot 2$ ). This contrast is reflected in the other variables of blood loss shown in table IV.

The third stage was much longer in the physiological group, lasting more than half an hour in a quarter of the women in this group compared with $3 \%$ in the active group (median length $15 v$ five minutes), and there was a greater need for therapeutic oxytocics in the physiological group $(29.7 \% v 6.4 \%)$. There were no significant differences between the groups in the need for manual removal of the placenta or subsequent evacuation of retained products of conception, or length of postnatal stay in hospital. In terms of side effects of the oxytocics, women allocated to active management were more likely to suffer from vomiting $(12 \% v 7 \%)$. Headaches and raised blood pressure were also more common in the active group, but the differences between the groups were not significant.

Apgar scores at one and five minutes were not significantly different between the groups. The mean birth weight of babies in the physiological group was $85 \mathrm{~g}$ higher than that of babies in the active group. Staff were more likely to request a blood sample (for indications such as polycythaemia and jaundice) from the babies in the physiological group (166 v 127); babies in the physiological group had a higher mean packed cell volume. The difference in the number of admissions to the special care nursery partly reflected the difference in the incidence of neonatal jaundice, but these differences were not significant. There was no difference in the incidence of neonatal respiratory problems between the two groups. Three quarters of the babies in both groups were breast feeding when they left hospital.

\section{SECONDARY ANALYSES}

In addition to the primary analyses (table IV) three further analyses were performed. Firstly, the data were reanalysed separately for the two time periods January to April 1986 inclusive and May 1986 to January 1987 inclusive-that is, before and after the changes in protocol recommended by the data monitoring group. The incidence of postpartum haemorrhage fell from $19 \%$ to $17 \%$ in the physiological group but rose in the active group from $3 \%$ to $7 \%$. The combination of these two changes had the effect of reducing the odds ratio of postpartum haemorrhage associated with physiological as compared with active management over the two time periods from $4.9(95 \%$ confidence interval 3.0 to $8 \cdot 1)$ to $2.5(1.7$ to 3.5$)$. This pattern was reflected for all the other variables of maternal blood loss but was less consistent for other variables.

In the next secondary analysis as prespecified in the trial protocol, the data were grouped according to whether the first and second stages of labour were considered low risk in relation to the third stage. These stages were defined as low risk if there was spontaneous onset of labour, augmentation and an epidural were unnecessary, labour lasted $<12$ hours, and delivery was spontaneous. The analysis was based on data obtained after the changes in the protocol as before

TABLE IV-Outcome in women allocated to physiological or active management of third stage of labour

\begin{tabular}{|c|c|c|c|c|}
\hline & $\begin{array}{c}\text { Physiological } \\
\text { management group } \\
(\mathbf{n}=849)\end{array}$ & $\begin{array}{l}\text { Active } \\
\text { management group } \\
(\mathrm{n}=846)\end{array}$ & Odds ratio & $\begin{array}{c}95 \% \\
\text { Confidence } \\
\text { interval }\end{array}$ \\
\hline \multicolumn{5}{|c|}{ Maternal variables } \\
\hline $\begin{array}{l}\text { No with postpartum haemorrhage } \geqslant 500 \mathrm{ml} \\
\text { No with postpartum haemorrhage } \geqslant 1000 \mathrm{ml} \\
\text { No with haemoglobin } \leqslant 90 \mathrm{~g} / \mathrm{l}(24-48 \text { hours post partum })^{\star} \\
\text { Mean (SD) haemoglobin } \\
\text { Mean (SD) fall in haemoglobin from value at } 34-37 \text { weeks' gestation }(\mathrm{g} / \mathrm{l}) \dagger \\
\text { Mean (SD) packed cell volume } \\
\text { No with postpartum haemorrhage during postnatal hospital stay } \\
\text { No who had blood transfusion } \\
\text { Mean (SD) No of units transfused } \\
\text { No whose third stage lasted }>30 \text { minutes } \\
\text { No given therapeutic oxytocic } \\
\text { No who had manual removal of placenta } \\
\text { No who had subsequent evacuation of retained products } \\
\text { No who vomited } \\
\text { No who had headache } \\
\text { No with diastolic blood pressure }>100 \mathrm{~mm} \mathrm{Hg} \text { in labour ward } \\
\text { Mean (SD) postnatal hospital stay (days) } \\
\text { No with serious problems in } 3 \mathrm{rd} \text { stage } \ddagger\end{array}$ & $\begin{array}{l}152 \\
26 \\
51 \\
111(14)^{\star \star \star} \\
6(13)^{\star \star \star} \\
0 \cdot 33(0 \cdot 04)^{\star \star \star} \\
18 \\
48 \\
0 \cdot 15(0 \cdot 66)^{\star \star} \\
221 \\
252 \\
22 \\
16 \\
55 \\
8 \\
8 \\
3 \cdot 4(2 \cdot 2) \\
178\end{array}$ & $\begin{array}{l}50 \\
7 \\
27 \\
117(22) \\
1(21) \\
0 \cdot 35(0 \cdot 04) \\
6 \\
18 \\
0 \cdot 07(0 \cdot 52) \\
25 \\
54 \\
16 \\
11 \\
102 \\
13 \\
17 \\
3 \cdot 4(2 \cdot 3) \\
70\end{array}$ & $\begin{array}{l}6 \cdot 42 \\
4 \cdot 83 \\
1 \cdot 38 \\
1 \cdot 45 \\
0 \cdot 52 \\
0 \cdot 62 \\
0 \cdot 48\end{array}$ & $\begin{array}{l}4 \cdot 90 \text { to } 8 \cdot 41 \\
3 \cdot 77 \text { to } 6 \cdot 18 \\
0 \cdot 72 \text { to } 2 \cdot 62 \\
0 \cdot 68 \text { to } 3 \cdot 10 \\
0 \cdot 37 \text { to } 0.72 \\
0 \cdot 26 \text { to } 1 \cdot 46 \\
0 \cdot 22 \text { to } 1 \cdot 06\end{array}$ \\
\hline \multicolumn{5}{|c|}{ Neonatal variables } \\
\hline $\begin{array}{l}\text { No with apgar score } \leqslant 6 \text { at } 5 \text { minutes } \\
\text { Mean (SD) birth weight }(g) \\
\text { Mean (SD) neonatal packed cell volume } \$ \\
\text { No with packed cell volume }<0.50 \S \\
\text { No with packed cell volume }>0.65 \S \\
\text { No admitted to special care nursery } \\
\text { No admitted for respiratory problems } \\
\text { No with jaundice (bilirubin }>428 \mu \mathrm{mol} / 1) \\
\text { No who were breastfeeding at discharge }\end{array}$ & $\begin{array}{l}8 \\
3422(444)^{\star \star \star} \\
0 \cdot 62(0 \cdot 08)^{\star \star \star} \\
11 \\
64 \\
64 \\
15 \\
54 \\
632\end{array}$ & $\begin{array}{l}8 \\
3337(451) \\
0.57(0 \cdot 07) \\
19 \\
15 \\
48 \\
14 \\
39 \\
637\end{array}$ & $\begin{array}{l}0.41 \\
3.87 \\
1.35 \\
1.07 \\
1.40 \\
0.96\end{array}$ & $\begin{array}{l}0.19 \text { to } 0.87 \\
2.30 \text { to } 6.51 \\
0.92 \text { to } 1.98 \\
0.51 \text { to } 2.23 \\
0.92 \text { to } 2.13 \\
0.77 \text { to } 1.19\end{array}$ \\
\hline
\end{tabular}

$\star$ Physiological management, $\mathrm{n}=694$; active management, $\mathrm{n}=685$.

†Physiological management, $n=627$; active management, $n=634$.

$\ddagger$ For example, blood loss $>500 \mathrm{ml}$, transfusion, manual removal of placenta, evacuation of retained products of conception

$\oint$ Physiological management, $n=166$; active management, $n=127$.

$\star \star p \leqslant 0 \cdot 01$.

$\star \star \star p \leqslant 0.001$ 
then information about use of epidurals was not available. The incidence of adverse variables was lower overall in the women defined as having low risk first and second stages. The direction of the effect of the policy of managing the third stage was the same in the groups with low and high risk first and second stages that is, proportionally more adverse variables occurred in the physiological than the active group. If anything, the size of this effect was consistently greater in the women defined as being at low risk - for example, in these women the incidence of postpartum haemorrhage was $16 \cdot 1 \%$ in the physiological group and $4 \cdot 4 \%$ in the active group (odds ratio $3.6 ; 95 \%$ confidence interval 2.2 to 5.9 ) whereas in the women defined as being at higher risk the incidence was $18.9 \%$ in the physiological group and $12.6 \%$ in the active group $(1 \cdot 6$; 0.9 to $2 \cdot 7$ ). A similar contrast was seen when any serious complication of the third stage was considered.

The final secondary analysis looked at the women who actually received the management to which they had been allocated. Data on women who received active management in the third stage (nearly all those allocated to it) were compared with data on the 403 women who received physiological management (just under half those allocated to it). Active management was still notably more beneficial in terms of postpartum haemorrhage (odds ratio $2.4 ; 1.6$ to 3.7 ) and any serious third stage problems, though these contrasts were less strong than those between the groups as randomly allocated. The differences were clearer in terms of the side effects of oxytocics such as vomiting and diastolic blood pressure $>100 \mathrm{~mm} \mathrm{Hg}$ in the labour ward. As most of the babies who needed to be seen by a paediatrician would have had their cords cut early the risk of being admitted to the special care nursery or having a packed cell volume $<0.50$ was reduced in the babies of women who received physiological management. In contrast, the odds ratio of a packed cell volume $>0.65$ was increased.

\section{Discussion}

In a recent paper Gilbert et al argued that postpartum haemorrhage is a continuing problem in Britain. ${ }^{14}$ The three years $1976-8$ saw the highest mortality due to postpartum haemorrhage since the mid-1960s. ${ }^{15}$ This rate fell again in 1979-81. ${ }^{16}$ The quoted incidences of postpartum haemorrhage vary widely throughout the United Kingdom from, for example, $4 \%$ in 1981 in Aberdeen City district ${ }^{17}$ to $11 \%$ in 1983-5 in Nether Edge Hospital, Sheffield. ${ }^{14}$ The reported national incidence for 1980 was $2 \% .^{18}$ This apparently low rate is probably at least partly because the diagnosis of postpartum haemorrhage is usually based on clinical estimation, which tends to underestimate blood loss. ${ }^{19}$

We were concerned that clinical estimates of blood loss might also be subject to systematic bias between the two trial groups as the observer could not be blinded to the management allocated. We therefore studied three maternal haematological variablesnamely, postpartum (24-48 hours) haemoglobin concentration $\leqslant 90 \mathrm{~g} / \mathrm{l}$, mean postpartum packed cell volume, and mean change in haemoglobin concentration between about 34 weeks' gestation and post partum. These indirect but objective variables supported the subjective clinical estimates.

Nearly all $(95 \%)$ the women eligible to participate in the trial did so, and the two groups were comparable at entry. There was a clear separation of management of the third stage between the two groups, with nearly all the women in the active group receiving all three main components of active management (prophylactic oxytocic, early clamping of the cord, and cord traction) compared with about half $(n=403)$ in the physiological group. We emphasise that this percentage is not a measure of non-compliance in the physiological group; the protocol specified the circumstances in which a deviation from the allocated management was allowed, and the reasons were documented. Rather this percentage may be seen as a measure of the outcome of the policy and these 403 women as the ones who succeeded in achieving a physiological third stage. The final secondary analysis showed, however, that even compared with physiological management in this "successful" group active management was notably more beneficial.

The remainder of the women in the physiological group consisted of those in whom physiological management was not attempted or failed. By considering the use of prophylactic oxytocic, the timing of cord clamping, and use of traction we estimated that about $17 \%$ of the women allocated to physiological management actually received as much active management as did those women allocated to active management. Hence the remaining 36\% represent the "failure" rate of implementing the policy of physiological management.

This failure may have several causes. It may be related to the categories of women included in the trial. Some people, notably $\operatorname{Inch}^{20}$ and the National Childbirth Trust, ${ }^{21}$ have argued against including women whose labour is induced or augmented or who have epidural anaesthetics, prolonged labour in the first or second stages, or an instrumental delivery. The results of our second secondary analysis showed that active management of the third stage was preferable regardless of these first and second stage criteria. If anything, and contrary to prior expectations, the advantage of active management was consistently greater in the women defined as being at low risk.

Another contribution to the rate of failure in implementing a physiological third stage may have been the way in which it was managed. This can be divided into four main components. Firstly, though the protocol for physiological management in the trial was established after considerable discussion with several proponents of such management, there is no standard definition of physiological management. Possibly some component of the package used in the trial was not entirely satisfactory.

Secondly, active management was the norm at this hospital before the study and few of the midwives were experienced in carrying out physiological management. One of us $(\mathrm{JH})$ therefore took advice from several midwives known to practise physiological management in the United Kingdom and then trained the midwives working in the delivery suite in this hospital for six weeks. A pilot study was conducted from November to December 1985 to ensure that the management was feasible. In addition, throughout the trial $\mathrm{JH}$ worked in close cooperation with the midwives on the delivery suite.

Thirdly, physiological management may have become less acceptable to the midwives as they became aware that it probably increased the incidence of postpartum haemorrhage and prolonged the length of the third stage. They had, however, to document their reasons for managing the third stage differently from the way it had been randomly allocated and were also aware that one of us $(\mathrm{JH})$ would be checking all these discrepancies. No reason was given for only 15 of the 446 women whose actual management was not as allocated. The remaining reasons were all legitimate as specified in the trial protocols.

Finally, although all women who were asked to participate in the trial were given a leaflet about possible advantages and disadvantges of active versus physiological management of the third stage of labour, they would almost certainly not have had any antenatal 
training about it. This may have been more important in the physiological group, in which maternal effort played a greater part.

Thus the main conclusion of the trial is that the policy of active management as practised in this hospital is justified. This is not just in terms of the primary outcome of blood loss greater than $500 \mathrm{ml}$ as this is not necessarily dangerous in generally healthy women. The increased risk with physiological management also applied to maternal blood loss greater than $1000 \mathrm{ml}$, the need for blood transfusions, longer third stages, and a raised neonatal packed cell volume (in those babies who were tested). In contrast physiological management was advantageous only in terms of reducing the incidence of vomiting and neonatal packed cell volumes of less than 0.5 . The sample size was not large enough to test the effect on other, rarer problems.

The views of midwives in the labour ward and of a sample of women participating in the trials were also assessed. They are reported fully elsewhere, ${ }^{22}$ but in summary they provided no evidence to counter the conclusions of the main trial. Depending on the extent to which the obstetric population in the trial and the management policies of this hospital are broadly comparable, these conclusions may be extrapolated to elsewhere in the United Kingdom.

Investigation is needed into some of the components of active management-for instance, to compare different oxytocics. ${ }^{23}$ Physiological management is the norm in most Third World countries. The role of particular aspects of this management needs to be researched-for instance, the role of early suckling, which is being considered in a trial in Malawi (C H W Bullough, personal communication).

Postpartum haemorrhge is still an important cause of maternal mortality in the Third World. Oxytocics, however, are unstable at high ambient temperatures. ${ }^{24}$ A study of the feasibility of active management in such settings is needed, followed by a trial of physiological versus active management. The experience of this trial after the changes in protocol (the first secondary analysis) suggests that it is important also to test whether using all aspects of active management rather than adopting a piecemeal approach is preferable. In Bristol inconsistent variations between the two time periods suggest that these may be a result of the smaller numbers in these analyses (616 for January to April and 1079 for May to January) compared with the total trial size of 1695 , especially as many of the changes were in the group allocated to active management, in which management had not changed. Possibly some real improvements in outcome occurred in the group allocated to physiological management, perhaps due to the changes in the protocol or to increased confidence of the midwives. This hypothesis needs to be formally tested in a randomised controlled trial of active versus physiological management of the third stage in a setting in which physiological management is the norm.

We thank the women who took part in the trial; the midwives on the central delivery suite; the obstetricians; Ralph Targett, Hazel Ashurst, and David Jenkins for computing; the data monitoring committee, Ian MacKenzie, Sally Garforth, and Adrian Grant; Colin Bullough, Geoffrey Chamberlain, Peter Dunn, Rick Guidotti, Sally Inch, Elizabeth Wilson and colleagues at the Department of Health and Social Security; colleagues at the national perinatal epidemiology unit; Philippa Claiden and Frances Potter for typing; South Western Regional Health Authority for financial support; and the many other people who helped. The maternity and child division at the World Health Organisation, Geneva, provided some additional funds. The national perinatal epidemiology unit is supported by the DHSS.
I Garcia J, Garforth S, Ayers A. The policy and practice of midwifery study: introduction and methods. Midwifery 1987;3:2-9.

2 Chamberlain GVP. Discussion. In: Chamberlain GVP, Orr CJB, Sharp F, eds. Litigation and obstetrics and gynaecology. London: Royal College of eds. Litigation and obstetrics and gynaecolo
Obstetricians and Gynaecologists, 1985:272.

3 Milton PJD. Natural childbirth and home deliveries-clinical aspects. In: Chamberlain GVP, Orr CJB, Sharp F, eds. Litigation and obstetrics and gynaecology. London: Royal College of Obstetricians and Gynaecologists, 1985:279-99

4 Dunn PM. The placental venous pressure during and after the third stage of labour following early cord ligation. Journal of Obstetrics and Gynaecology of the British Commonwealth 1966;73:747-56.

5 Dunn PM. Postnatal placental respiration. Dev Med Child Neurol 1966;8:607.

6 Dunn PM. Caesarean section and the prevention of respiratory distress syndrome of the newborn. In: Bossart $\mathrm{H}$, ed. Perinatal medicine: report of the third European congress of perinatal medicine, Lausanne. Berne: Hans Huber, 1973:138-45

7 Dunn PM. Management of childbirth in normal women: the third stage and fetal adaptation. In: Clinch J, Matthews T, eds. Perinatal medicine: report of the ninth European congress of perinatal medicine, Dublin. Lancaster: MTP Press, 1985:47-54.

8 Dunn PM, Fraser ID, Raper AB. Influence of early cord ligation on the transplacental passage of foetal cells. Foumal of Obstetrics and Gynaecology of transplacental passage of foetal cells. Foum

9 Inch S. Management of the third stage of labour-another cascade of intervention? Midwifery 1985;1:114-22.

10 Prendiville $W$, Elbourne D, Chalmers $I$. The effects of routine oxytocic administration in the management of the third stage of labour: an overview of the evidence from controlled trials. Br $\mathcal{F}$ Obstet Gynaecol 1988;95:3-16.

11 Romney M, White V. Current practices in labour. In: Field P, ed. Perinatal nursing. Edinburgh: Churchill Livingstone, 1984. (Recent Advances in Nursing, Vol 8.)

12 Houlton M, Austin J, Jenkins D, Turner G, Wilkins D. A microcomputer in the delivery suite. Brf Obstet Gynaecol 1984;91:555-9.

13 Yusuf S, Peto R, Lewis J, et al. Betablockade during and after myocardial infarction: an overview of the randomised controlled trials. Prog Cardiovasc Dis 1985;27:335-71.

14 Gilbert L, Porter W, Brown V. Postpartum haemorrhage-a continuing problem. Br f Obstet Gynaecol 1987;94:67-71.

15 Department of Health and Social Security. Report on confidential enquiries into maternal deaths 1976-1978. London: HMSO, 1982.

16 Department of Health and Social Security. Report on confidential enquiries into matemal deaths 1979-1981. London: HMSO, 1986.

17 Hall $\mathrm{MH}$, Halliwell R, Carr-Hill R. Concomitant and repeated happenings of complications of the third stage of labour. Br F Obstet Gynaecol 1985;92: $732-8$.

18 Office of Population Censuses and Surveys, Department of Health and Social Security, Welsh Office. Maternity hospital in-patient enquiry. Maternity tables 1977-1981, England and Wales. London: HMSO, 1986.

19 Newton M, Mosey LM, Egli GE, Gifford WB, Hull CT. Blood loss during and immediately after delivery. Obstet Gynecol 1961;17:9-18.

20 Inch S. Physiology of the third stage of labour. Midwives Chronicle and Nursing Notes 1988; February:42-3.

21 National Childbirth Trust. The third stage of labour: physiology and management. London: National Childbirth Trust, 1985.

22 Harding JE, Elbourne DR, Prendiville WJ. Views of mothers and midwives participating in the Bristol randomised controlled trial of active management participating in the Bristol randomised controt
of the third stage of labor. Birth (in press).

23 Elbourne D, Prendiville W, Chalmers I. Choice of oxytocic preparation for routine use in the management of the third stage of labour: an overview of routine use in the management of the third stage of labour: an overview
the evidence from controlled trials. Br $\mathcal{F}$ Obstet Gynaecol 1988;95:17-30.

24 Longland P, Roebotham PC. Stability at room temperature of medicines normally recommended for cold storage. Pharmaceutical fournal 1987;228: $147-51$

(Accepted 15 August 1988)

\section{ONE HUNDRED YEARS AGO}

It is a distressing fact that, while there are a number of homes for female inebriates in England, some of which receive patients without means, there has been practically no provision for destitute male inebriates, or even for those of limited resources. But one attempt at providing for such men has been made, the history of which is before us. Lieutenant-Colonel Whale took a farm at Crowboro about sixteen months ago, and received in all some eleven inmates; six of these were destitute and paid nothing, the others paid ten shillings per week. Unfortunately, the financial support was not sufficient to sustain the undertaking, and the founder has been compelled to close the house, after having expended $£ 300$ beyond the donations, subscriptions, and payments for board received by him. He is now appealing for $£ 500$ to enable him to discharge his liabilities and open the farm afresh. . . . It is essential to success to recognise the diseased condition of the inebriate, and to treat him therapeutically with a view to cure. Provided that the bodily and mental affection be attended to, no better adjunct than an industrial farm can be employed. Healthful exercise in the open is an excellent plan to divert into a proper channel that exuberance of spirits and energy which a period of abstinence soon develops in the abstaining inebriate.

(British Medical Fournal 1888;ii:381) 